\author{
V. Spadaro, M. Pasqualetti, A. S. Faqi \& F. M. Raimondo
}

\title{
From ethnobotany to experimental research: the therapeutic properties of Sicilian hellebore*
}

\begin{abstract}
Spadaro, V., Pasqualetti M., Faqi, A.S. \& Raimondo F.M.: From ethnobotany to experimental research: the therapeutic properties of Sicilian hellebore . — Bocconea 28: 393-398. 2019. — ISSN: 1120-4060 printed, 2280-3882 online.

The Sicilian hellebore (Helleborus bocconei subsp. intermedius) is an endemic plant of the family Ranunculaceae from southern Italy and Sicily. This plant is known for the traditional use of dried rhizomes for treating pneumonia in domestic animals, cattle and horses in particular. In recent years, this plant was subject to various ethnobotanical, phytochemical, morpho-anatomical and mycological investigations. In addition, lately, was evaluated antibacterial activity of Chaetomium strumarium strain RR1, an endophytic ascomycete of this plant.

On the whole, the different phases of this study are here reported and can be interrelated. However, they support our initial hypothesis, that the therapeutic effect of the hellebore's rhizomes extract is due to metabolites reputedly produced by an endophytic fungus.

Key words: Helleborus bocconei subsp. intermedius, Ranunculaceae, endemic plant, endophytic fungi, folk veterinary medicine, pneumonia.
\end{abstract}

\section{Introduction}

Nowadays, the main objective of ethnobotany is to document traditional knowledge about plants before it disappears and to explore and preserve the heritage of the folk medicine (Cámara-Leret \& al. 2014). On the basis of the documentation of indigenous knowledge on the folk use of plants, in some countries ethnobotanical surveys have been used for the discovery of new drugs. The further development of these phytotherapeutical resources comes just from the experimental research.

The biological and ethnopharmacobotanical study on Sicilian hellebore can also be seen in this context (Spadaro 2006).

The medicinal properties and the toxic effects of some species of the genus Helleborus L. were pointed out by different authors. In Sicily, according Pignatti (1982), the genus Helleborus (Ranuculaceae) is only represented by H. bocconei subsp. siculus (Schiffner)

*Article first published online on 20 December 2018 in Flora Mediterranea 28: 247-252. 
Merxm. \& Podl [= Helleborus bocconei subsp. intermedius (Guss.) Greuter \& Burdet], commonly known as Sicilian hellebore or "radicchia". In some mountainous areas of the Island, the rhizomes of this plant, harvested in a particular month of the year (May) and dried, are used in traditional veterinary practice for treating pneumonia in domestic animals, cattle and horses in particular (Raimondo \& Lentini 1990). The same use - with rhizomes of other Helleborus species or subspecies - is reported from various other areas of Mediterranean Europe (Viegi \& al. 2003).

According to the traditional knowledge on this medicinal remedy in some rural communities, it was considered appropriate to carry out experimental researches on $H$. bocconei subsp. intermedius from Sicily in order to highlight the therapeutic effect on which is based the local use of the hellebore's dried rhizomes in the folk veterinary medicine for treating pneumonia in domestic animals.

\section{Materials and methods}

This study is referred to $H$. bocconei subsp. intermedius (Fig.1) and subsequently to Chaetomium strumarium (J. N. Rai, J. P. Tewari \& Mukerji) P. F. Cannon RR1 (Fig. 2).

The examined materials were collected in different seasons, between April and September 2010, in the locality Grotta del Garrone, near Monte Pizzuta (Piana degli

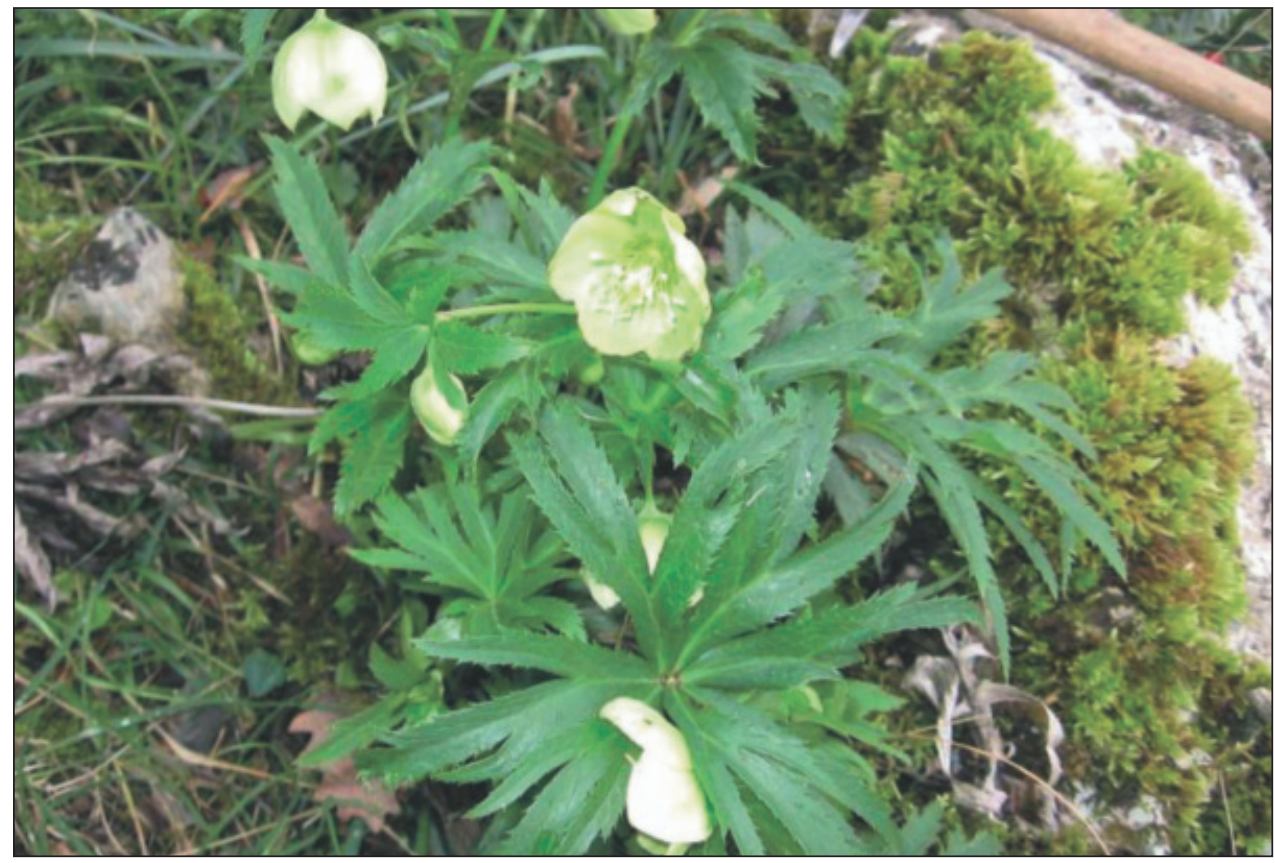

Fig. 1. Helleborus bocconei subsp. intermedius in the locality Grotta del Garrone (Piana degli Albanesi, Palermo). 


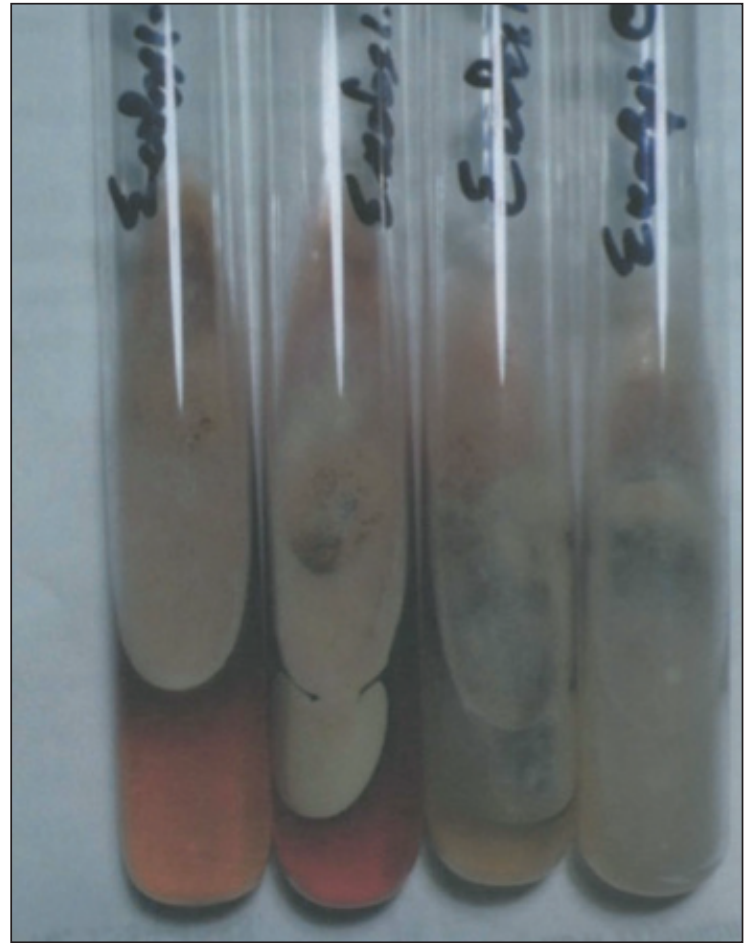

Fig. 2. Chaetomium strumarium strain RR1: colony on Mycological agar.

Albanesi, Palermo). A voucher specimen (No. 3/10) is kept in PAL (Spadaro \& al. 2014).

C. strumarium RR1, an endophytic fungus, was isolated from different organs (root, rhizome, stem and leaf) of $H$. bocconei subsp. intermedius with surface-sterilizing method (Bayman \& al. 1997). Molecular characterization of the strain RR1 endophyte, a nonsporulating fungus, based on the internal transcribed spacer (ITS) region of the rRNA gene sequences was done (Spadaro \& al. 2014).

This microfungus maintained as stock culture was utilized in the antibiotic property assays. The strain was maintained in Czapek-Dox Agar (DIFCO) plate at $27^{\circ} \mathrm{C}$ and transferred to a new medium at 15 days intervals.

\section{Results and discussion}

The results of the various investigations have been extremily promising. Phytochemical tests have permitted the isolation and characterization of new biologically active molecules; in particular, two new furostanol saponins helleboroside A and helleboroside B were isolated from the hellebore's rhizomes methanolic extract along with the furospirostanol saponin and two ecdysones: ecdysterone and polypodyne B (Spadaro 2006; Rosselli \& al. 2006). The extracts of rhizomes and aerial parts of the plant showed antibacterial properties (Rosselli \& al. 2007). Some compounds, specifically furostanol saponins and ecdyso- 
nes, isolated from the methanolic extract of the rhizomes, were tested against rat $\mathrm{C} 6$ glioma cells showing a significant cytotoxicity (Rosselli \& al. 2009). Additional, morpho-anatomical studies have revealed the presence of different endophytic and commensal fungi in all organs of the plant (Fig. 3), which could be isolated and cultured. One of the isolates has been identified as the endophytic fungus Ciborinia allii (Sawada) L. M. Kohn (sub: Botrytis byssoidea J. C. Walker), which is also widely present in soil (Spadaro \& al. 2007). Further fungal isolates include C. strumarium, strain RR1, an endophytic ascomycete the identity of which was confirmed by molecular analyses (Spadaro \& al. 2014). This endophyte was constantly found and - by preliminary antibiosis assays - has a remarkable antibacterial activity not on a single species but on the complex of species commonly present in soil (Spadaro \& al. 2011). When cultured, it developed plentifully; in Mycological agar, the development of RR1 strain is rapid, tumultuous, perfectly centrifugal. RR1 endophyte produced only sterile mycelium and was not taxonomically identifiable by morphological study. To obtain sporulation different media were utilized PDA, CYA and MEA 2\%. No sexual or asexual reproductive structures were observed; in MEA 2\% cultures up to 90 days old, some pseudoparenchymatous hyphal aggregations cleistotecial-like, were observed. For taxonomic attribution the strain was subjected to the molecular analysis of ITS region (Spadaro \& al. 2014). Recently, the filtered broth from these cultures was used in antibiotic property assays (Spadaro \& al. 2011); the tests were positive. In recent literature (Ranadive $\&$ al. 2013), C. strumarium is reported among the fungi with antimicrobial activity.

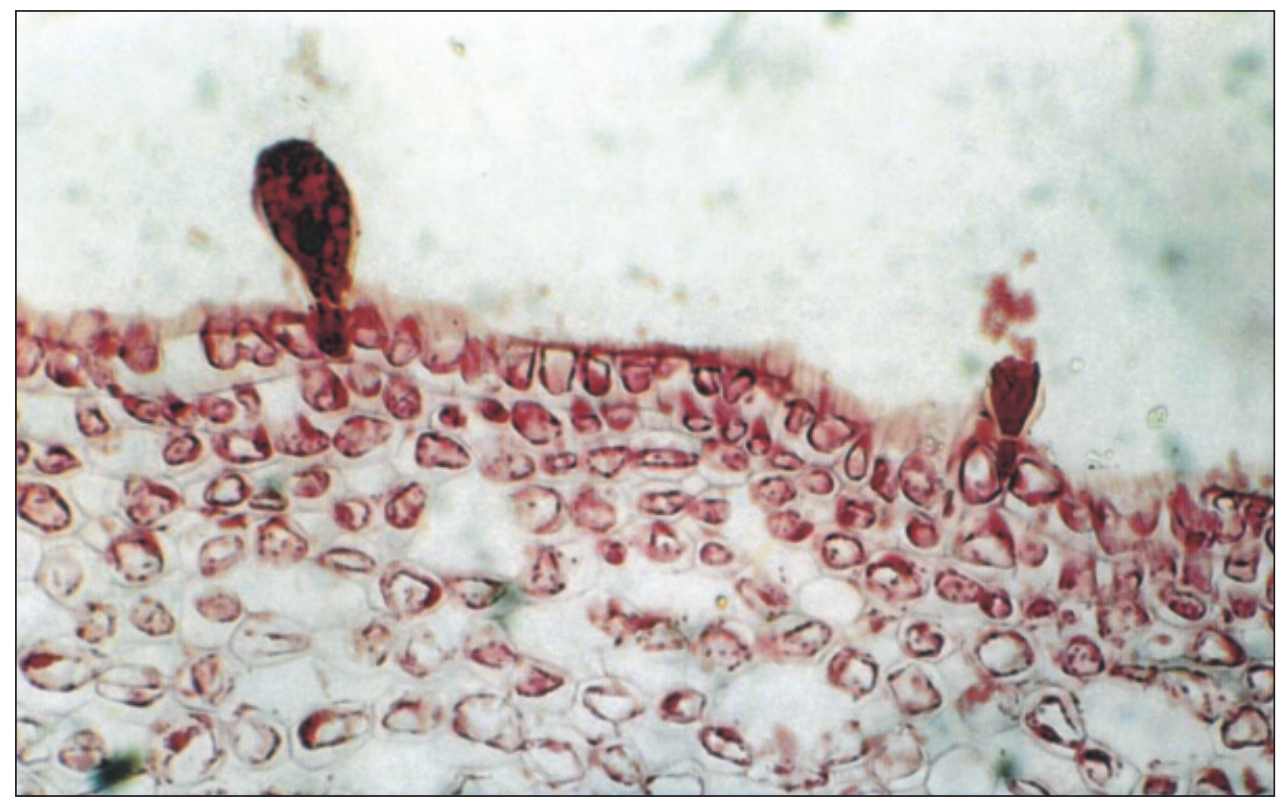

Fig. 3. Detail of cross section of floral peduncle of Helleborus bocconei subsp. intermedius $(\times 200)$ highlighting pseudoparenchymatous hyphal aggregations of the endophyte. 


\section{Conclusions}

As evidenced by the results, this study was particularly stimulating for significant elements of biological and ethnopharmacobotanical importance. Firstly, it is very important the relationship between endophytic microorganisms and Sicilian Hellebore in order to explain the traditional use of dried rhyzomes of $H$. bocconei subsp. intermedius in the veterinary treatment of pneumonia in domestic animals. According to these findings and considering the importance of endophytic microorganisms as sources of new biologically active molecules, further mycological analyses of $H$. bocconei subsp. intermedius from Sicily are considered advisable (Spadaro \& al. 2014).

Particular attention was given to the antibacterial activity of C. strumarium strain RR1, one of the endophytic microfungi isolated from this plant and resulted recurrent in the subsequent isolations. In fact, this interesting endophyte grows in the living tissues of the host plant and therefore. we studied the mycelium development and tested the antibacterial activity. The filtered broth from these cultures was used in antibiotic property assays. The tests were positive; the detailed results are forthcoming. They support our initial hypothesis, that the therapeutic effect of the hellebore's rhizome extract is due to metabolites produced by an endophytic fungus. This phenomenon appears particularly relevant and could explain the antibacterial activity of the plant in the folk veterinary medicine.

It remains to be seen whether the plant itself, devoid of the microfungus, produces the same therapeutically effective metabolites that are present in the extracts of plants from the wild or from outdoor cultivation. The study of the Sicilian hellebore, beyond its biological interest, has potential for its relevance for therapeutic applications both in veterinary and human medicine.

\section{References}

Bayman, P., Lebron, R., Tremblay, L. \& Lodge, J. D. 1997: Variation in endophytic fungi from roots and leaves of Lepanthes (Orchidaceae). - New Phytologist 135: 143-149.

Cámara-Leret, R., Paniagua-Zambrana, N., Balslev, H. \& Macía, M. J. 2014: Ethnobotanical Knowledge Is Vastly Under-Documented in Northwestern South America. - PLoS ONE 9(1): e85794. doi: 10.1371/journal.pone.0085794

Pignatti, S. 1982: Flora d'Italia, 1. - Bologna.

Raimondo, F. M. \& Lentini F. 1990: Indagini etnobotaniche in Sicilia. I. Le piante della flora locale nella tradizione popolare delle Madonie (Palermo). - Naturalista Sicil., s. 4, 14(3-4): 77-99.

Ranadive, R. K., Belsare, H. M., Deokule, S. S., Jagtap, V. N., Jadhav, K. H. \& Vaidya, G. J. 2013: Glimpses of antimicrobial activity of fungi from World. - J. New Biol. Rep. 2(2): 142-162.

Rosselli, S., Maggio, A., Senatore, F., Spadaro, V. \& Bruno, M. 2006: Indagine fitochimica sulle radici di Helleborus bocconei Ten. subsp. intermedius. - P. 134 in: Atti XV Congresso ItaloLatinoamericano di Etnomedicina. - Perugia-Roma.

—, - Formisano, C, Napolitano, F., Senatore, F, Spadaro, V. \& Bruno, M. 2007: Chemical Composition and Antibacterial Activity of Extracts of Helleborus bocconei Ten. subsp. intermedius. - Nat. Prod. Comm. 2(6): 675-679. doi: 10.1016/j.jep.2009.06.011

—, - Bruno, M., Spadaro, V., Formisano, C., Irace, C., Maffettone, C. \& Mascolo, N. 2009: Furostanol Saponins and Ecdysones with Cytotoxic Activity from Helleborus bocconei ssp. intermedius. - Phytoterapy Res. 23: 1243-1249. doi: 10.1002/ptr.2569 
Spadaro, V. 2006: Studio biologico ed etno-farmacobotanico di Helleborus bocconei subsp. intermedius (Ranunculaceae). - Tesi di dottorato, XVIII ciclo. Università di Palermo.

—, Raimondo, F. M. \& Colombo, P. 2006: Studio etnofarmacobotanico di Helleborus bocconei subsp. intermedius (Ranunculaceae): aspetti morfoanatomici. - P. 107 in: Atti $101^{\circ}$ Congresso S.B.I. - Caserta.

—, - \& - 2007: Endophytic evidences in Helleborus (Ranunculaceae). - Fl. Medit. 17: 277- 289.

—, Tempesta, S., Colombo, P., Raimondo, F. M. \& Rambelli, A. 2007: An interesting endophyte isolated from Helleborus bocconei subsp. intermedius (Ranunculaceae) in Sicily. - P. 195 in: Results XII OPTIMA Meeting. - Pisa.

-, Raimondo, F. M., Rambelli, A. \& Trapani, F. 2011: Attività antibatterica di un endofita di Helleborus bocconei subsp. intermedius (Raunculaceae). - P. 224 in: Atti $106^{\circ}$ Congresso S.B.I. - Genova.

—, Raimondo F. M. \& Pasqualetti M. 2014: Molecular and taxonomic characterization of a endophytic fungus isolated from Helleborus bocconei subsp. intermedius (Ranunculaceae). - Fl. Medit. 24: 71-78. doi: 10.7320/FIMedit24.071

Viegi, L., Pieroni, A., Guarrera, P. M. \& Vangelisti, R. 2003. A review of plants used in folk veterinary medicine in Italy as basis for a databank. - J. Etnopharm. 89: 221-224.

Addresses of the authors:

Vivienne Spadaro ${ }^{1}$, Marcella Pasqualetti ${ }^{2}$, Ali Said Faqi ${ }^{3}$ \& Francesco M. Raimondo ${ }^{4}$, ${ }^{1}$ Department STEBICEF/Section of Botany and Plant Ecology, University of Palermo, Via Archirafi 38, 90123 - Palermo, Italy.

${ }^{2}$ Department DEB, University of Tuscia, Via S.M. in Gradi 4, 01100 - Viterbo, Italy. ${ }^{3}$ Wayne State University, School of Medicine, Department of OBGYN, Detroit, U.S.A.

${ }^{4}$ PLANTA/Research, Documentation and Training Center, Piazza Cairoli 11, 90123 - Palermo, Italy. 